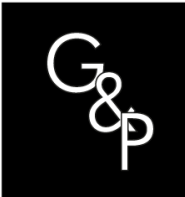

\title{
Comparative analysis of the main business process modeling methods: a bibliometric study
}

\author{
Análise comparativa das principais metodologias de modelagem de processos de \\ negócios: um estudo bibliométrico
}

\author{
Tulio Cremonini Entringer ${ }^{1}$ (1) , Ailton da Silva Ferreira ${ }^{1,2}$ (1), \\ Denise Cristina de Oliveira Nascimento ${ }^{2}$ (B)
${ }^{1}$ Universidade Estadual do Norte Fluminense Darcy Ribeiro - UENF, Laboratório de Engenharia de Produção - LEPROD, Campos dos ailtonsilvaferreira@id.uff.br \\ Goytacazes, RJ, Brasil. E-mail: tulio_entringer@hotmail.com \\ 2Universidade Federal Fluminense - UFF, Departamento de Administração, Macaé, RJ, Brasil. E-mail: ailtonsilvaferreira@yahoo.com.br
}

How to cite: Entringer, T. C., Ferreira, A. S., \& Nascimento, D. C. O. (2021). Comparative analysis of the main business process modeling methods: a bibliometric study. Gestão \& Produção, 28(2), e5211. https://doi.org/10.1590/1806-9649-2020v28e5211

\begin{abstract}
The offer of business process modeling methodologies is quite extensive, making it difficult for scholars in the BPM area to choose properly. In this context, this paper has the objective to present the main modeling methodologies, with applications, examples and comparisons. A systematic bibliographic survey and the comparative analysis of these notations used in the implementation of BPM projects have been carried out. According to the bibliometric analysis, the modeling notations of the business process most portrayed in the works surveyed are: BPMN, UML, EPC and IDEF. From the construction of a consistent overview that allows the comparative analysis of the methodologies, in order to select the one that suits better its specificities it can be verified that, although they share the same objective, each notation has its specific characteristics. This study has the main purpose of providing a basis for the adequate indication of the application of studies in the field, especially those destined for papers, dissertations and theses.
\end{abstract}

Keywords: BPM; Business processes modeling; Business processes methodology.

Resumo: A oferta de metodologias de modelagem de processos de negócios é bastante extensa, dificultando os estudiosos da área de BPM uma escolha adequada. Nesse contexto, este artigo tem o objetivo de apresentar as principais metodologias de modelagem, com aplicações, exemplos e comparações. Foi realizado um levantamento sistemático bibliográfico e análise comparativa dessas notações utilizadas na implementação de projetos BPM. De acordo com a análise bibliométrica, as notações de modelagem de processos de negócio mais retratadas nos trabalhos levantados são: BPMN, UML, EPC e IDEF. A partir da construção de um overview consistente que permita a análise comparativa das metodologias, a fim de selecionar aquela que mais se adequa às suas especificidades pode-se verificar que, embora partilhem o mesmo objetivo, cada notação tem as suas características específicas. Este estudo possui propósito principal de servir de base para a indicação adequada a aplicação de estudos na área, em especial aos destinados a papers, dissertações e teses.

Palavras-chave: BPM; Modelagem de processos de negócios; Metodologia de processos de negócios.

\section{Introduction}

Since the 1990s, organizations have experienced an evolution in terms of structural and technological models, bringing new paradigms to the changes and knowledge (Silva, 2015). This fact has been requiring a new stance on the personal and managerial styles, focused on a different and emerging reality. In this sense, contemporary companies are gradually starting to organize themselves in a way oriented to the processes that permeate them, following their logic, and no longer the departmental reasoning of the functional approach (Malamut, 2005).

Today there is a highly competitive environment in the organizational world, which leads the current organizations to implement mechanisms that promote in a quickly and effectively way the development and 
optimization of their information systems. Indeed, the agility factor is increasingly an aspect of differentiation between companies, to act and respond in advance to the market pressures, needs and opportunities.

Thus, companies started to focus on their business processes in order to present high levels of competitiveness and they realize that these processes are key factors of organizational success. A Business Process Management (BPM) approach through a set of organized activities ensures greater control, flexibility and the ability to align processes with organizational strategy (van der Aalst, 2013). One of these activities present in this approach is the business process modeling that has the ability to define and change organizational processes in a more logical and structured way (Silva, 2015).

The offer of different types of process modeling methodology is quite extensive, making it difficult for project modelers to make an appropriate choice. In this sense, Silva (2015) conducted a study to produce a support solution for the analysis of business process modeling notations, in order to facilitate the selection of a methodology in the process modeling stage.

This paper has the objective to analyze the main business modeling methodologies, from a systematic bibliographic survey, and to present the comparative discussion of these main methodologies used in the implementation of BPM projects in organizations, based on the study performed by Silva (2015), with the main purpose of serving as a basis for indicating the appropriate methodology for the application of BPM projects. Additionally, these results are configured as a theoretical framework for application in papers, dissertations and theses.

The paper is organized as follows: section 2 discusses the theoretical framework on Business Process Management and Business Process Modeling; section 3 presents the research method applied in the paper; section 4 presents the results of the bibliometric analysis, highlighting the main methodologies applied in the context of BPM; section 5 presents a comparative analysis of the main Business Process Modeling Methodologies based on the study performed by Silva (2015); and lastly, section 6 presents the final considerations of this paper.

\section{Theoretical reference}

\subsection{Business Process Management - BPM}

BPM is a holistic management approach (Draghici et al., 2012) developed with a strong focus on the adoption of the Information Technology (IT) (vom Brocke \& Sinnl, 2011). The methodologies, techniques or tools used act by designing, approving, controlling, as well as analyzing business processes involving the organization, human beings, applications, documents and any other source of information (Pyon et al., 2011), being increasingly most used by organizations to promote the effectiveness and efficiency of their business (Huang et al., 2011). In addition, according to Toor \& Dhir (2011), it strives to pursue innovation, flexibility and integration with technology, all with a focus on aligning the organization with the customer needs.

BPM can also be assessed as a continuous, structured, analytical, and multisectoral process improvement, which has several critical factors (Trkman, 2010), which are associated with various methods that enable companies to institute high business process orientation (Skrinjar \& Trkman, 2013). It is noteworthy how important is the understanding and involvement of top management, the recognition of information systems, well-defined responsibilities, as well as a culture that is receptive to business processes (Draghici et al., 2012).

According to Siriram (2012) understanding, BPM demands a systemic and balanced view, as the business process binds the organization, resulting in a harmonization of resources, such as processes, people and systems. For the author, BPM actions require the assimilation of a niche area, so that one can target critical processes that are aligned with the organization's strategic objectives.

According to the Association of Business Process Management Professionals, BPM is a management discipline as a structured approach to identifying, executing, measuring, monitoring and controlling business processes whether automated or not, to achieve consistent and targeted results by aligning business processes to the organization's strategic goals, creating value, and enabling the organization to achieve its business goals more quickly (ABPMP, 2015).

For Repa \& Bruckner (2015), BPM is a well-established management model for manage the business process lifecycle, including design, execution and analysis. Haddar et al. (2014) complement this definition, indicating that BPM is based on the design of a model that meets a set of quality criteria, which is a non- 
trivial task due to the complexity of current Business Processes. In fact, the heterogeneity of these types of projects motivated the search for approaches to assist in the design of high quality models at reduced costs.

BPM, in Arevolo's (2006) considerations, seeks to map and improve the company's business processes through a lifecycle approach consisting of the definition, modeling, testing, distribution, execution, monitoring, analysis phases, and business process optimization, as illustrated in Figure 1.

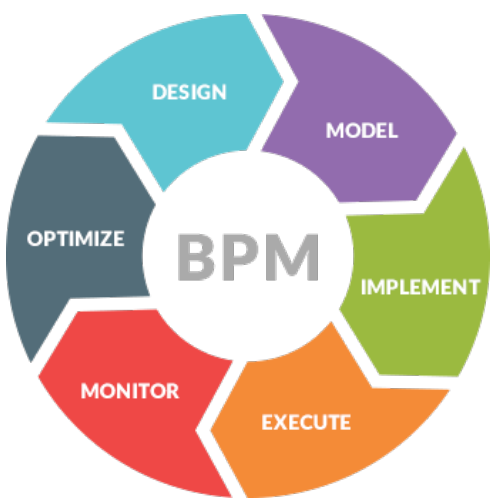

Figure 1. BPM macroprocesses. Source: adapted from Arevolo (2006).

Studies in the area of BPM approach this organizational model as a global business view and highlight the transition from functional management to process-oriented management, suggesting the application of BPM from a systemic approach, highlighting the inter- relationships of processes in their contexts. That said, unnecessary and misdirected steps are eliminated and refurbished, employing the resources available in the main processes (Segatto et al., 2013).

Note that in order to achieve the desired effectiveness, it is important that BPM is not only approached as a simple set of IT tools, but as an environment in which a process-oriented view and the means of communication that requires the business organization as a whole (Cho \& Lee, 2011). This requires a wellorganized team (Neubauer, 2009), knowledge of processes in their individual or collective form (Seethamraju, 2012), and a good selection of crucial processes (Cho \& Lee, 2011).

Finally, it is observed that to understand the operation of processes and what types exist, it is essential to determine how they should be managed in order to obtain the best result (Siriram, 2012). Thus, to reproduce an organizational structure by processes, it is necessary to have a defined scenario of the company through the mapping of the activities, rules and relationships that make up the processes, as well as an appropriate business process modeling methodology.

\subsection{Business process modeling}

Process modeling is an organization's process representation activity that allows analysis of its current form so that it can be improved in the future (Toor \& Dhir, 2011), as organizations need to understand them (Abu Rub \& Issa, 2012) to be able to improve them. A modeling is useful for describing and graphing the important aspects of a given process, distinguishing people, departments and the link between them (Climent et al., 2009), in order to portray or represent them properly, emphasizing the aspects. that need to be reported and dealt with (Vergidis et al., 2008).

In general, process modeling aims to describe business process characteristics, highlighting their structure, the sequence of activities and their relationships, the resources used, among others. Therefore, this activity presents itself as an important facilitator of the understanding and analysis of processes (Abu Rub \& Issa, 2012) and has been widely used by organizations to document and improve their operations (Smirnov et al., 2012).

For Silveira et al. (2016), process modeling has been developed as a technology to describe processes such that they can be understood and developed with greater transparency. Through this modeling it is possible to plan, create procedures and document them consistently, enabling to demonstrate the reality of the company and make changes according to desirable future situation (Leopold et al., 2016).

According to Pinggera et al. (2015), real process models present a wide range of problems that converge on a model's syntactic, semantic, and pragmatic quality dimensions. For the authors, syntactic and semantic quality relates to model construction and addresses the correct use of the modeling language and the extent 
to which the model truly represents real-world behavior, respectively. In addition, pragmatic quality addresses the extent to which a model supports its use for purposes such as understanding behavior and system development.

In order to capture the different aspects that constitute a business process, it is necessary to use appropriate process modeling methodologies, techniques and standards (Cull \& Eldabi, 2010). Process modeling methodologies are a set of graphical constructs and rules on how to combine such elaborations. In this universe of business process modeling methodologies, there are from very simple languages to extremely sophisticated languages. For Georges (2010), the most sophisticated business process modeling methodologies are those designed for the development of information systems, whether these are transactional systems, supervisory systems or workflow management systems. Some of the key techniques available are: Business Process Modeling Notation (BPMN), Unified Modeling Language (UML), Eventdriven Process Chain (EPC), and Integration DEFinition (IDEF) (Toor \& Dhir, 2011).

BPMN is the largest and most widely accepted business process modeling methodology (Pavani \& Scucuglia, 2011). It is the set of graphical conventions for describing business processes, specifically designed to coordinate process sequence and message exchange between processes. Zhang et al. (2012) agree with this idea by pointing out that BPMN represents processes in a standardized way, facilitating the understanding of the organization's stakeholders and employees. According to Rachdi et al. (2016), BPMN is an emerging modeling method that has received much interest and support from academia and industry as an open standard for Business Process Modeling. In addition to being one of the latest modeling notations standardized by OMG (Object Management Group) and BPMI (Business Process Management Initiative), BPMN is considered user-friendly for all stakeholders in the organization (Kocbek et al., 2015) and allows to model a business process with a single type of Business Process Diagram (BPD). It is worth noting that this notation used to model the current situation of processes called AS-IS (current state). With the capabilities offered by the notation, are performed process simulations that allow the activities to be automated easily and quickly with control through visual indicators, thus generating a proposed model with improvements known as TO-BE (future state) (Scheruhn et al., 2015).

UML emerged from the union of three modeling methodologies: the Booch method, the Object Modeling Technique (OMT) method and the Object-Oriented Software Engineering (OOSE) method (Torres, 2011). This technique was developed for the purpose of being a graphical notation for the analysis, specification, construction and documentation supporting software development. The main challenge in the development phase of this notation was to create a standardized language with unique semantics to be able to represent systems of different levels of complexity (Geambaşu, 2012). For Booch et al. (2006), the UML is also expressive enough to model non-software systems, such as workflow, structure and behavior of systems and hardware designs. The success of this methodology has contributed to the adoption of UML models in several systems development initiatives, which include requirements approaches that use business process information often represented in adapted UML diagrams (Torres, 2011).

EPC is also one of the most widely used business process modeling languages worldwide (Devillers 2011). It is a notation that was developed in 1992 by researchers at the University of Saarland in partnership with SAP, one of the world's leading powers in integrated management software production (Mili et al., 2010). Like most process modeling notations, the EPC also resembles in its structure flowcharts for the representation of logical and temporal dependencies between activities in business process construction (Keletso et al., 2014). The main focus of this notation is to allow its users an intuitive graphical representation of organizational processes that is quick and simple for both process analysts and business people to understand (Van Wel, 2013). In addition, EPC is the core business process representation language of the Architecture of Integrated Information Systems (ARIS) methodology, which aggregates business-related resources and organizes them to ensure the development of business sequences and tasks that produce value (Davis \& Brabander, 2007). Pavani \& Scucuglia (2011) consider the EPC a simple and easy to understand methodology, very similar to flowcharts.

Finally, we highlight the IDEF technique, which originated from an initiative of the United States Department of Defense aimed at creating a method that would allow modeling requirements for systems. It was first used in the 1970s and later standardized by the National Institute of Standards and Technology. This methodology allows the analysis of processes by building models that reflect their current functionality to project the ideal business operational situation (Almeida, 2009). IDEF is composed of 16 techniques for modeling and systems analysis, initially designed for use in Software Engineering. Each of these techniques is used in different application areas, however IDEF0, which is more focused on modeling business functions, and IDEF3, which specifically models business processes, are in fact the two most useful notations that can complement each other in process modeling (Costin \& Fox, 2004). 


\section{Methodology}

\subsection{Bibliometric analysis}

To define the main business process modeling methodologies, the bibliometric review research method proposed by Marasco (2008) was used. For the composition of the bibliographic portfolio, the Scopus databases were defined. Research was conducted in journals without temporal delimitation of published studies. The total number of papers found in these databases was the result of combinations of keywords searched, titles and abstracts.

In the definition of keywords for the literature review, the keywords "Business Process Modeling" AND "Business Process Management" OR "BPM" were used, as shown in Table 1.

Table 1. Keywords of bibliometric research.

\begin{tabular}{c}
\hline "Business Process Management” \\
\hline OR “BPM” AND “Business Process Modeling”
\end{tabular}

Source: Authors.

The works found with these two combinations of terms were mostly chapters of journal articles, books, norms and congress articles, which will present the results of the bibliometric review. Thus, 243 studies were obtained.

\subsection{Comparative analysis}

Business process modeling methodologies have different characteristics, strengths and limitations. Therefore, it is important to find a way to compare them in order to systematize their differences and similarities.

To carry out the comparative analysis of business process modeling methodologies, an extensive review of the relevant literature that deals with the characterization of business process modeling methodologies was elaborated. Different authors use different criteria to evaluate process modeling methodologies, although some criteria tend to be more or less universal (Silva, 2015), which are:

- Expressiveness: seeks to assess language for its ability to represent, and is therefore a criterion especially focused on the elements of each notation in order to assess whether these elements serve all the purposes and needs of the most varied models, from the simplest to the most complex;

- Formalism: associated with the fact that there is a formal description and definition of each notation. That is, whether or not each notation has a formal definition of all its elements, as well as clear rules on the use of each;

- Usability: aims to measure how difficult it is to understand and use process modeling notation for both analysts and modelers. It is a criterion that promotes the ease of use of ratings;

- Friendliness: this criterion is concerned with the importance of the graphical aspect of the notation used, ie a notation that is not too complex in relation to the elements and relationships between them should be sought;

- Readability: understood as the ease of interpreting processes by all stakeholders, such as business analysts, technical and non-technical modelers of these processes, as well as the management of organizations themselves;

- Flexibility: the presence of graphics that allow a high level of flexibility and give various modeling alternatives is a factor favored by some modelers;

- Support Tools: verifies that the language you choose has a variety of support solutions for your implementation;

- Universality: in choosing a particular process modeling notation, it analyzes whether the notation is sufficiently recognized in a broad universe, assuming some benefits such as greater support from an active community or closer proximity to the user and developer; 
- Purpose: in a study of the choice of modeling notation to adopt it is very important to understand what is intended to be done with the final models, ie, it is necessary that the language allows the automation and execution of the processes or just perform analysis and manipulations on processes, for example.

\section{Main methodologies business process modeling}

Considering Business Process Management as a fundamental object of this review, we highlight the Business Process Modeling Methodologies most discussed in the papers raised in the Scopus database from the bibliometric review, which are: BPMN, UML, EPC and IDEF.

The BPMN methodology stands out for being present in about $55 \%$ of these published works, as shown in Figure 2, followed by UML (21\%), EPC (12\%) and IDEF (7\%), while the other methodology adds up to $5 \%$. The results of a survey by Kocbek et al. (2015) also showed that BPMN is the default language in the process modeling field.

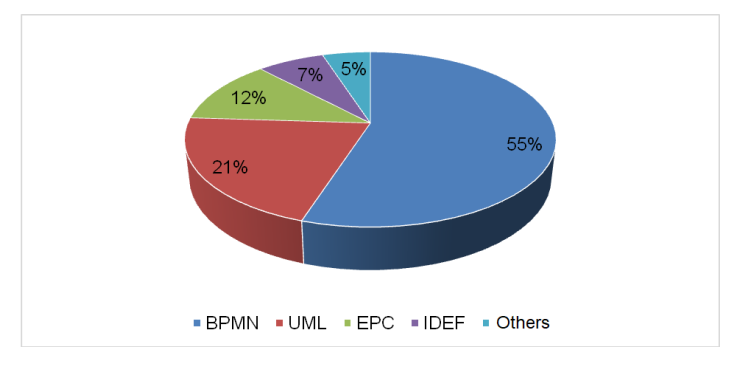

Figure 2. Business Process Modeling Methodologies covered in papers in the Scopus database. Source: Authors.

In the following subtopics, the main methodologies raised from the bibliometric review applied in this study will be addressed, highlighting works present in the scientific literature with the application of such notations.

\subsection{Business process modeling notation}

Recent works with BPMN applications include publications in the following areas: health (Onggo et al., 2018), manufacturing (Witsch \& Vogel-Heuser, 2012), offshore (Joschko et al., 2015), industrial (Petrasch \& Hentschke, 2016), educational (Strîmbei et al., 2016), e-commerce (Bukhsh et al., 2017), service (Geiger et al., 2016), etc.

Joschko et al. (2015) described a holistic approach to Operation and Maintenance (O\&M) processes in the field of offshore wind farm power generation. Process acquisition and visualization is performed by a risk analysis of all relevant processes. From then on, a tool was designed that is able to model the processes defined in a BPMN notation, as well as to connect and simulate them. In addition, the notation was enriched with new elements, representing other relevant factors that could only be displayed with much greater effort. Figure 3 shows the return travel process modeling by personnel transfer ship. 


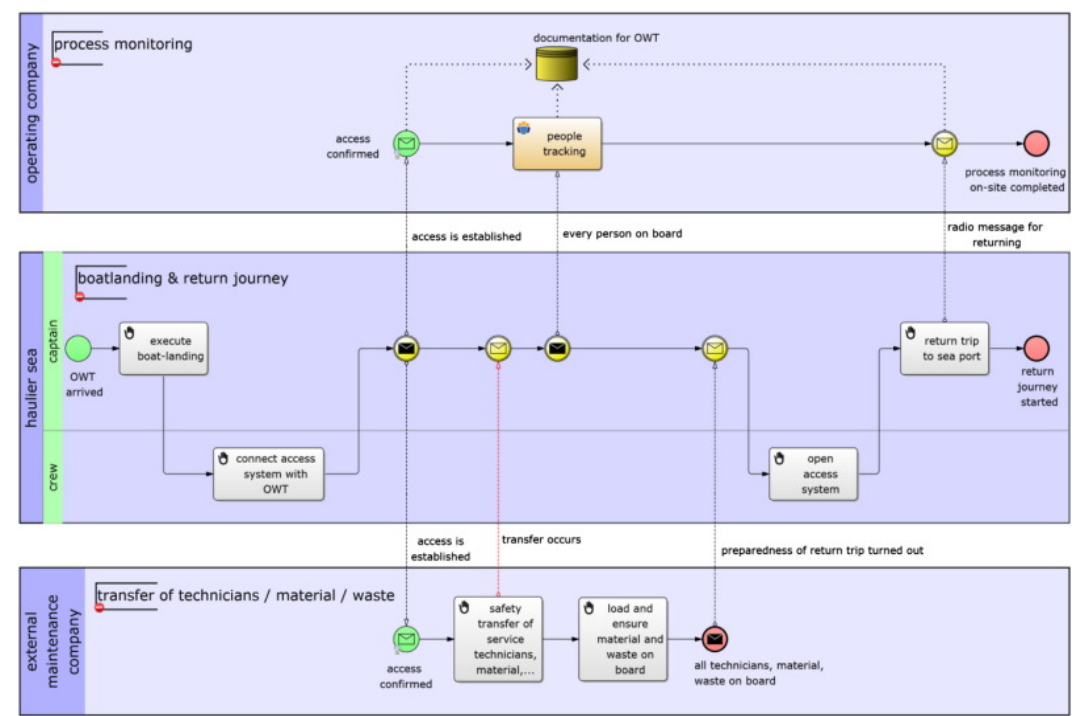

Figure 3. Modeling of return trip process by personnel transfer ship. Source: Joschko et al. (2015).

Strîmbei et al. (2016) provided a new insight into corporate modeling in the context of BPMN and the university area. This study reveals a BPMN-specific approach in the context of university information systems, based on a comparative analysis of some representative universities in the United States and Central Europe. The authors present 4 realistic and complex systems: curriculum and programs, student admission, student roadmaps, student exchanges. Figure 4 shows the BPMN modeling for the student exchange process.

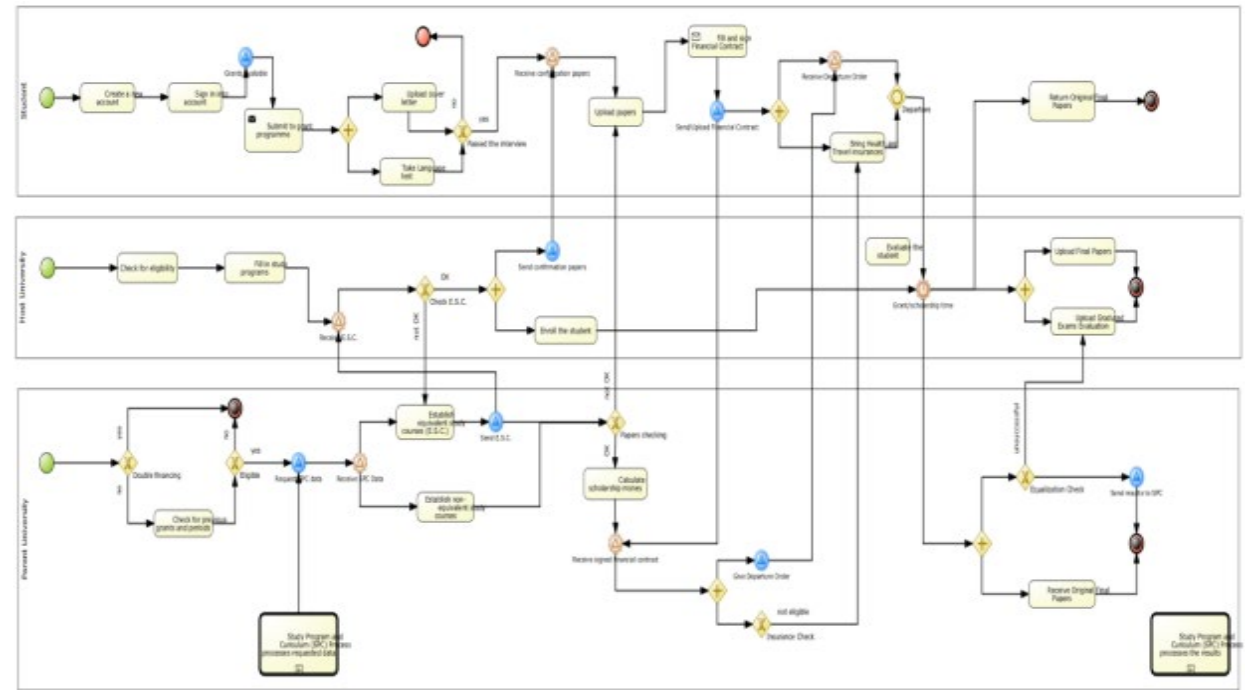

Figure 4. BPMN modeling for student exchange process. Source: Strîmbei et al. (2016).

\subsection{Unified modeling language}

Recent publications on the UML methodology include work on applications in education (De Lope \& Medina-Medina, 2016), health (Ferrante et al., 2013), industry (Latif et al., 2011), services (Zheng et al., 2014), e-commerce (Maman et al., 2017), etc.

Ferrante et al. (2013) performed the modeling of the post-stroke rehabilitation process. In healthcare organizations where rehabilitation procedures are provided for stroke patients, further workflow detail is needed. The proposed model, implemented in UML, is based on international guidelines and has been refined following the clinical path adopted at the local level by a specialized rehabilitation center. This model describes the organization of rehabilitation delivery and facilitates recovery monitoring during the process. The flexibility of the model guarantees an easy update after the process evolution. Figure 5 shows the class diagram of the rehabilitation process of the study in question. 
Zheng et al. (2014) developed and designed a library management system based on the UML modeling engine to analyze a simple library management system. The authors state that UML can efficiently convey information among users, developers, designers and managers, which improves their collaboration capabilities and increases the degree of industrialization in software development projects. The design process indicates that as a software engineering modeling language, UML has a very good application perspective. Figure 6 discusses the UML class diagram of book loan management design.

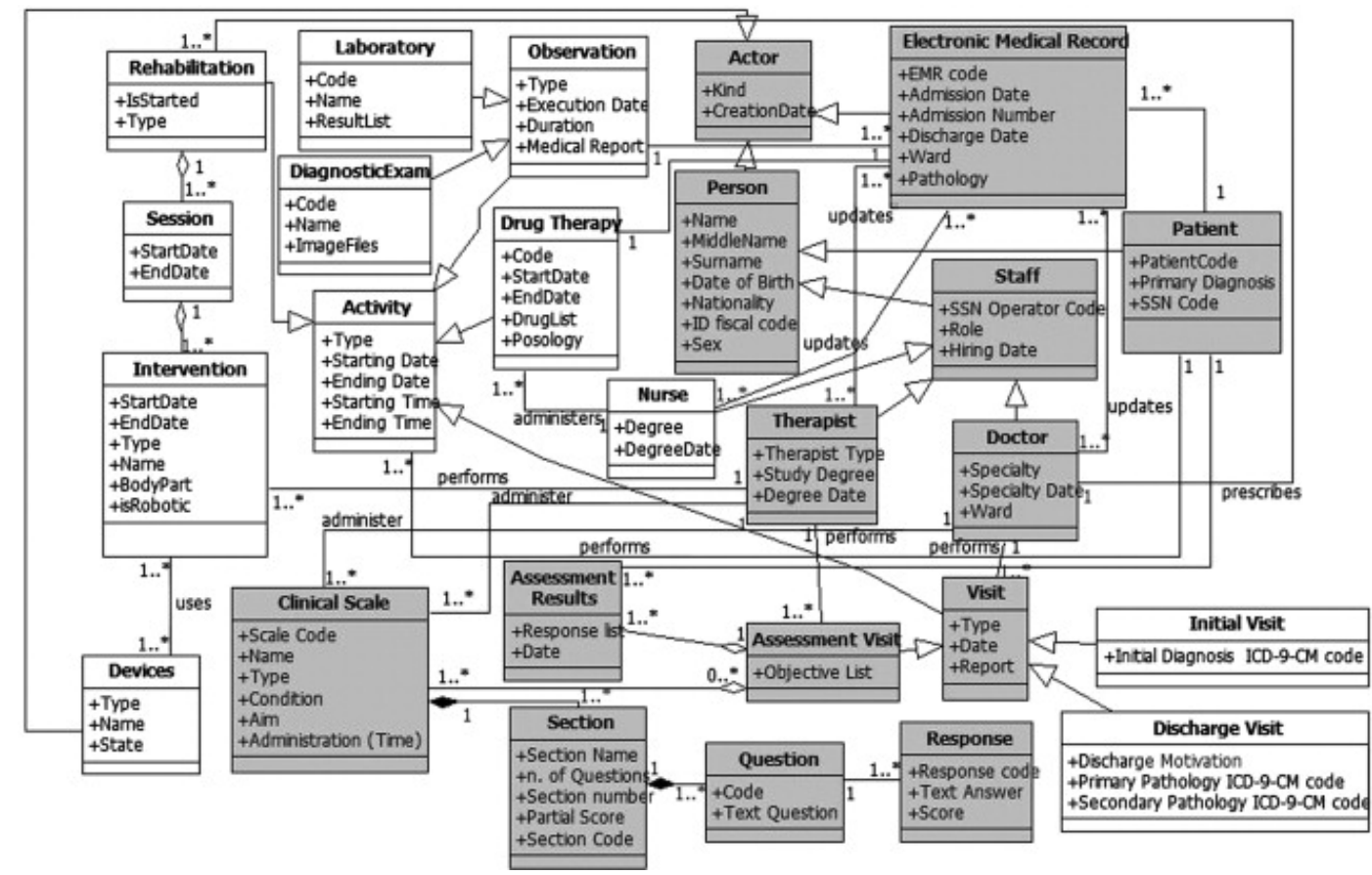

Figure 5. UML process modeling - class diagram of the post stroke rehabilitation process. Source: Ferrante et al. (2013).

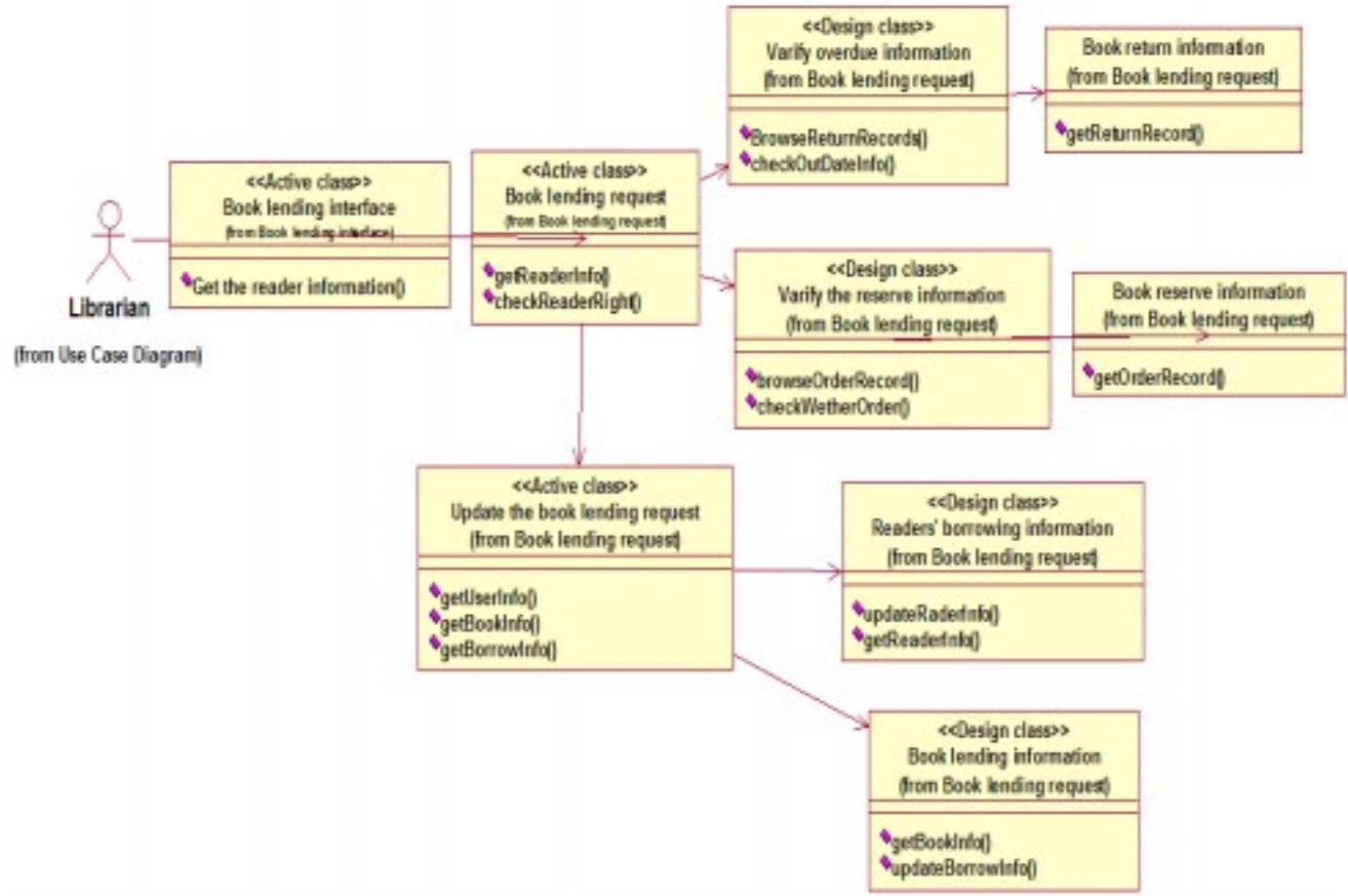

Figure 6. Diagram design classes of the management book loans. Source: Zheng et al. (2014). 


\subsection{Event-driven process chain}

Among the works raised from the literature review that use the EPC methodology, we highlight the publications with applicability in the following areas: services (Giviani \& Argourd, 2015), supply chain (Mohammadi \& Mukhtar, 2012), education (Rostanski, 2013), marketing (Fleacă et al., 2016), health (Zarabzadeh et al., 2012), among others.

Giviani \& Argourd (2015) mapped the processes of the technical treatment division of the São Carlos Integrated Library System, a municipality in the state of São Paulo, Brazil, from its acquisition to its availability to the user, who is responsible for receiving works, classification and indexing, tipping, availability in the collection and inventory of all bibliographic material of the libraries of the system. For this, the authors made use of business process modeling through the EPC methodology. Figure 7 shows the macroprocessing of library inventorying activity.

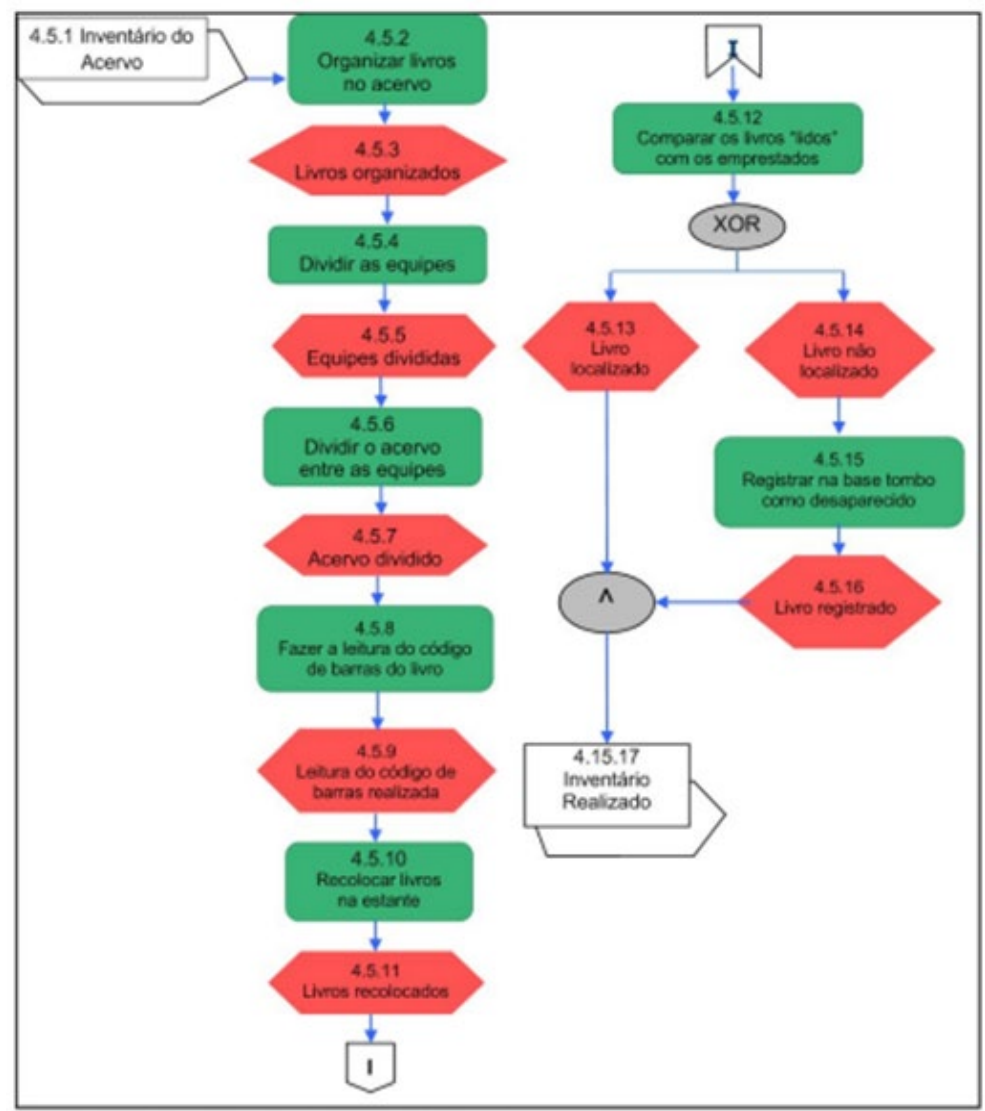

Figure 7. Macro-modeling of library inventory activities. Source: Giviani \& Argourd (2015).

Fleacă et al. (2016) applied the EPC methodology to model the variables of an organization's marketing research process. The findings highlight the benefits of the marketing research workflow that increases the value of market intelligence while reducing the costs of consistently obtaining it. The authors also highlight the high impact on stakeholder satisfaction. This paper aims to decipher modern trends in business process management and innovation and provides a useful marketing research process diagram using the BPMN graphical vocabulary EPC tool (Figure 8). 


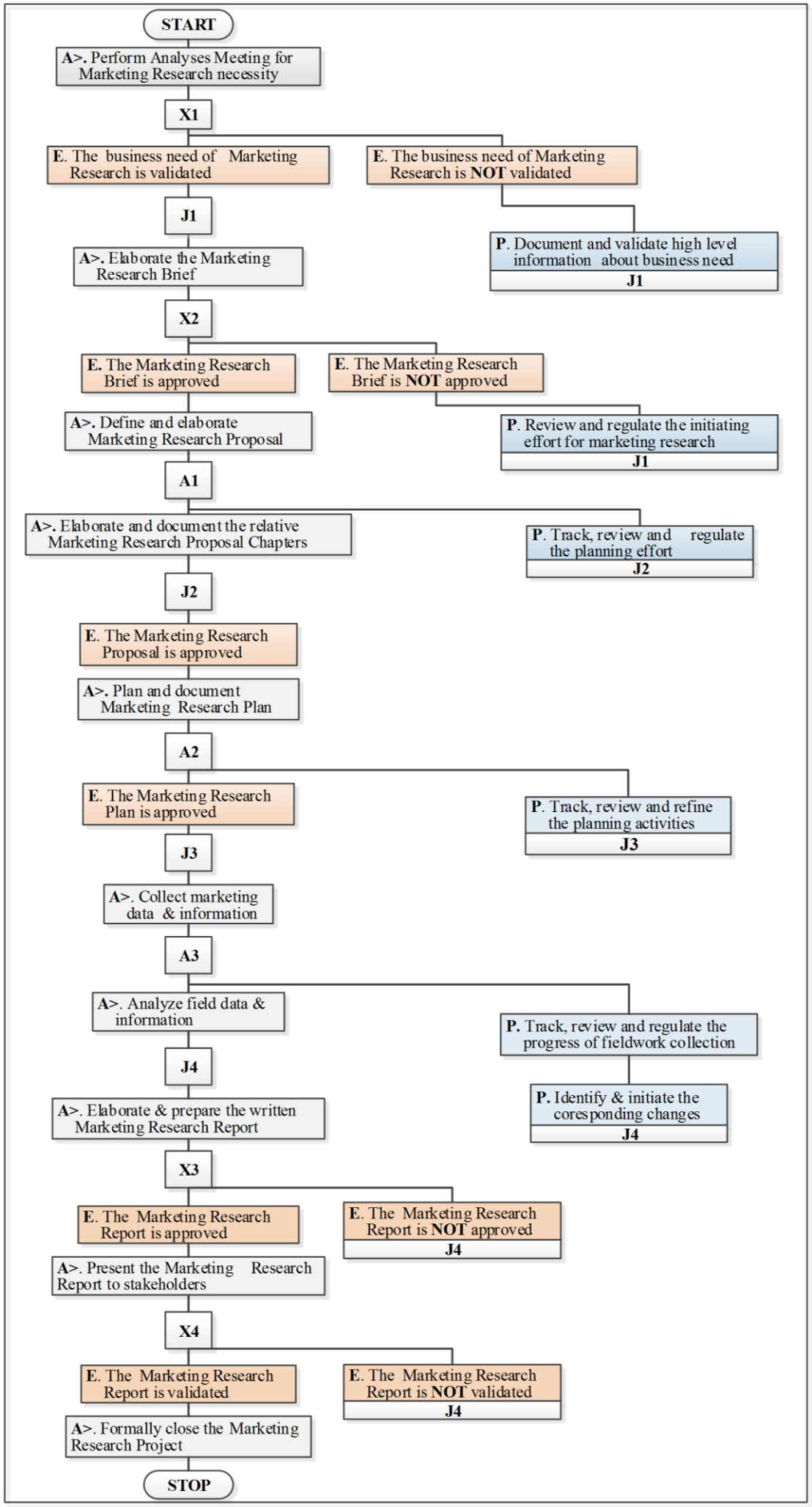

Figure 8. EPC modeling of BPMN graphic vocabulary - Marketing research process diagram. Source: Fleacă et al. (2016).

\subsection{Integration definition}

Among the publications on the IDEF methodology stand out the works with applications in manufacturing (Pinarbaşi et al., 2013), industrial (Kuo et al., 2012), supply chain (Kuo et al., 2014), building construction (Tas et al., 2008), etc. 
Pınarbaşı et al. (2013) studied flexible manufacturing systems (FMS). The authors proposed an FMS design approach using the IDEF. A systematic layout scheme and a performance appraisal scheme are presented and detailed using this modeling framework. Then the proposed approach was carried out with a case study of an aircraft industry to convert an existing traditional production system into FMS. The goal was to find the machine and product mix that achieve maximum utilization while minimizing cycle time. From the IDEF model, it was observed that FMS system performance was greatly improved by determining the most advantageous level of system components. Figure 9 shows the IDEF context diagram layout design and benchmarking.

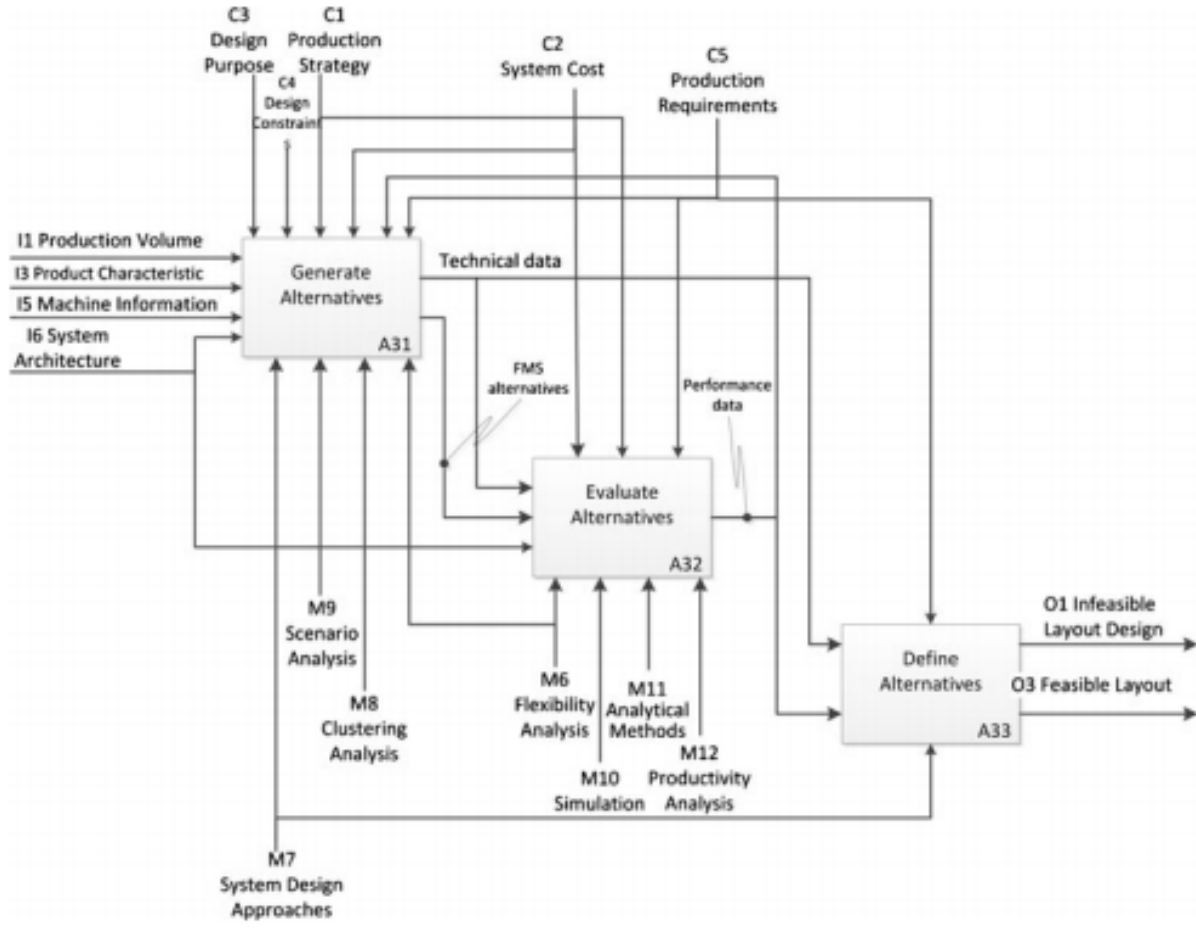

Figure 9. IDEF modeling: context diagram layout design and performance appraisal. Source: Pinarbaşi et al. (2013).

Ciurana et al. (2008) developed a model that can be applied after the development of an integrated process planning and programming tool using an IDEF methodology to design an activity model, which integrates process planning and production in metal removal processes. An activity model was used to develop a system that allows the user to plan process and production at the same time in a collaborative engineering work. To design the business model, a wide range of parts was evaluated and processed at a real workshop factory. Several activities have been developed in detail to be tested in real cases. Figure 10 shows the process planning level in the IDEF model. 


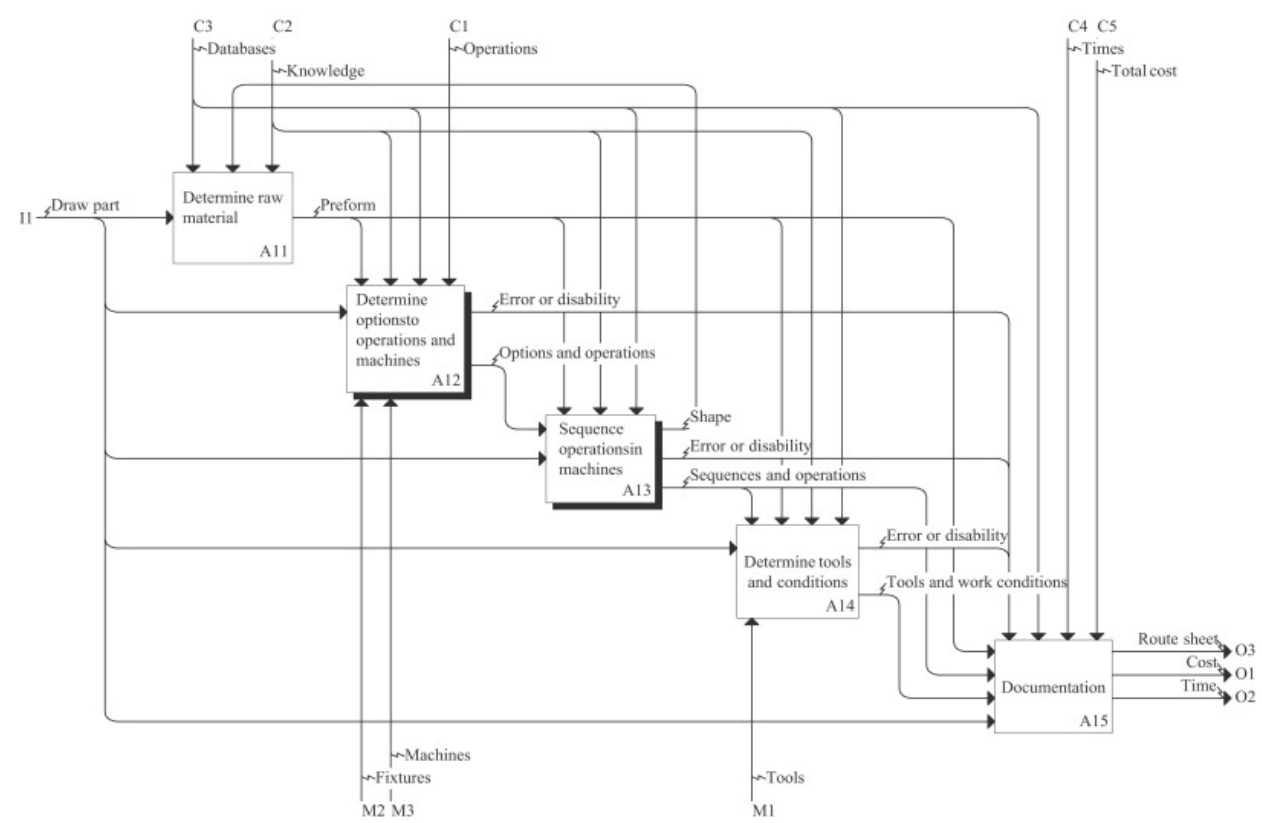

Figure 10. Process planning level in the IDEF model. Source: Ciurana et al. (2008).

The following section discusses a comparative analysis of the main business process modeling methodologies raised in this paper - BPMN, UML, EPC and IDEF - based on the study by Silva (2015).

\section{Comparative analysis of methodologies}

From systematic analytical studies by authors from the business process modeling area, Silva (2015) listed these works in each of the comparative criteria addressed in this study, in order to highlight the characterization of business process modeling methodologies. Table 2 presents an adapted version of Silva (2015) of the characteristics of each of the methodologies raised from the bibliometric analysis.

Table 2. Evaluative criteria of business process modeling methodologies.

\begin{tabular}{|c|c|c|c|c|}
\hline Expressiveness & $\mathbf{x}$ & $x$ & $x$ & $x$ \\
\hline Usability & $\mathbf{x}$ & $x$ & $\mathbf{x}$ & $\mathbf{x}$ \\
\hline Friendliness & $\mathbf{x}$ & & & \\
\hline Flexibility & $\mathbf{x}$ & & & \\
\hline Support Tools & $\mathbf{x}$ & $\mathbf{x}$ & $\mathbf{x}$ & \\
\hline Universality & $\mathbf{x}$ & $\mathbf{x}$ & $\mathbf{x}$ & \\
\hline Purpose & $\mathbf{x}$ & $\mathbf{x}$ & $\mathbf{x}$ & $\mathbf{x}$ \\
\hline
\end{tabular}

Source: Authors.

From the study of systematization of the analysis of the comparative criteria mentioned, carried out by Silva (2015) in the specific literature, the criterion of "Expressiveness of languages" is the criterion that has received the most attention by the authors surveyed. Thus, it is verified that the capabilities of the methodologies raised allow to represent the most diverse organizational situations, either in behavioral, functional, structural or informational terms.

The criteria "Formalism", "Usability", "Readability" and "Purpose" were also related to the functionalities of the four methodologies raised in this study. Thus, it can be stated that BPMN, UML, EPC and IDEF are business process modeling methodologies that are easily understood and interpreted by users; focuses 
mainly on the complexity of language use; reduces or removes ambiguities in model interpretation; and that the relevance of the purpose of the model is easily perceived and understood.

BPMN stood out for being the only methodology to meet the criteria "Friendly" and "Flexibility". Thus, it is observed that such methodology presents a graphically pleasant notation that can help the users work, facilitating the identification of the intended and necessary elements to meet the expected result for the final model; and allows for a high level of flexibility and offers several modeling alternatives for users.

Finally, it is noteworthy that the BPMN, UML and EPC methodologies have the criteria "Supporting Tools" and "Universality", according to the literature approached by Silva (2015), about business process modeling methodologies. Thus these three notations present a multitude of solutions to support their implementation, have several widely used software packages that allow the business process analyst to have a professional tool and tested by various organizations; They are also sufficiently recognized in the business community, in the academic community and in terms of market outreach, with implications for their use support.

\section{Final considerations}

The main objective of this paper was to present, based on theoretical references, a review about the main business process modeling methodologies, from the systematic bibliographic survey in this area of study and the discussion of the comparative analysis of such methodologies.

The use of a process modeling methodology for business process documentation has numerous advantages, usually related to techniques and standards, created solely to support business process design and that aim to optimize the process modeling task. For a better performance in this area of process modeling it was clear that it is crucial to use a specific methodology for this purpose.

Thus, according to bibliometric research, the most prominent business process modeling methodologies featured in the papers surveyed are: BPMN, UML, EPC and IDEF. Among the papers present in the Scopus database, the BPMN stands out for being present in most of these published studies, and these results are corroborated by Kocbek et al. (2015), who highlight that BPMN is the standard language in the field of process modeling.

Unlike other techniques, BPMN is a standard designed to provide a notation that is more easily understood and used by everyone involved in business processes, and is a comprehensive technique that provides modeling capabilities for a wide range of processes, from the most generic to the most specific.

Through a selection of the most important modeling methodologies in this area it was possible to verify, from examples of applications analyzed, that, although they share the same objective, each methodology has its specific characteristics. Thus, a comparative analysis of business process modeling methodologies proposed by Silva (2015) was exposed, based on a comprehensive review of the relevant literature that focuses on the characterization of methodologies, based on the selection of different evaluation criteria.

Finally, it is concluded that the main purpose in building a consistent overview that, in the face of a certain organizational context or BPM project, allows the comparative analysis of the process modeling methodologies, in order to select the one that best fits their specificities. This solution will allow more informed selection of the notation to serve certain purposes by the project team without the need for a major study of the various existing languages. Thus, it is enough to indicate, among the various criteria identified, those that for your project or organizational context seem most important to you, giving them the corresponding appreciation. Additionally, these results are configured as a theoretical framework for application in papers, dissertations and theses.

\section{References}

ABPMP. (2015). Pesquisa Nacional em Gerenciamento de processos de Negócio da ABPMP Brasil. Revista BPM Global Trends, 2.

Abu Rub, F. A. A., \& Issa, A. A. (2012). A business process modeling-based approach to investigate complex processes: software development case study. Business Process Management Journal, 18(1), 122-137. http://dx.doi.org/10.1108/14637151211215046.

Almeida, N. M. A. (2009). Técnicas de modelagem: uma abordagem pragmática. In R. Valle \& S. B. Oliveira (Eds.), Análise e modelagem de processos de negócio: foco na notação BPMN (Business Process Modeling Notation) (1. ed., Vol. 1, pp. 52-76). São Paulo: Atlas.

Arevolo, W. (2006). Building a business case for BPM. São Paulo: Gartner. 
Booch, G., Rumbaugh, J., \& Jacobson, I. (2006). UML: guia do usuário (2. ed.). Rio de Janeiro: Elsevier.

Bukhsh, Z. A., Van Sinderen, M., Klaas, N. S., \& Quartel, D. (2017). Understanding modeling requirements of unstructured business processes. In ICETE 2017 - Proceedings of the 14th International Joint Conference on eBusiness and Telecommunications (Vol. 2, pp. 17-27). Switzerland: Springer International Publishing.

Cho, C., \& Lee, S. (2011). A study on process evaluation and selection model for business process management. Expert Systems with Applications, 38(5), 6339-6350. http://dx.doi.org/10.1016/j.eswa.2010.11.105.

Ciurana, J., Garcia-Romeu, M. L., Ferrer, I., \& Casadesús, M. (2008). A model for integrating process planning and production planning and control in machining processes. Robotics and Computer-integrated Manufacturing, 24(4), 532-544. http://dx.doi.org/10.1016/j.rcim.2007.07.013.

Climent, C., Mula, J., \& Hernández, J. E. (2009). Improving the business processes of a bank. Business Process Management Journal, 15(2), 201-224. http://dx.doi.org/10.1108/14637150910949452.

Costin, B., \& Fox, C. (2004). Hybrid IDEF0/IDEF3 modelling of business processes: syntax, semantics and expressiveness. In Romanian-Austrian Workshop on Computer-Aided Verification of Information Systems: a Practical Industry-Oriented Approach (pp. 3-5). Austria.

Cull, R., \& Eldabi, T. (2010). A hybrid approach to workflow modeling. Journal of Enterprise Information Management, 23(3), 268-281. http://dx.doi.org/10.1108/17410391011036067.

Davis, R., \& Brabander, E. (2007). Platform, ARIS design: getting started with BPM. London: Springer.

De Lope, R. P., \& Medina-Medina, N. (2016). Using UML to model educational games. In Proceedings of the 8th International Conference on Games and Virtual Worlds for Serious Applications (VS-Games 2016). Piscataway: IEEE. http://dx.doi.org/10.1109/VS-GAMES.2016.7590373.

Devillers, M. (2011). Business process modeling the business-IT divide (Master's thesis). Radboud University, Nijmegen.

Draghici, A., Draghici, G., Olariu, C., \& Canda, A. (2012). Romanian market acceptance for business process management skills development. Procedia Technology, 5, 537-546. http://dx.doi.org/10.1016/j.protcy.2012.09.059.

Ferrante, S., Bonacina, S., \& Pinciroli, F. (2013). Modeling stroke rehabilitation processes using the Unified Modeling Language (UML). Computers in Biology and Medicine, 43(10), 1390-1401. http://dx.doi.org/10.1016/j.compbiomed.2013.07.012. PMid:24034730.

Fleacă, E., Fleacă, B., \& Maiduc, S. (2016). Fostering Organizational Innovation based on modeling the Marketing Research Process through Event-driven Process Chain (EPC). EM Journal, 5(4), 460-466.

Geambaşu, C. V. (2012). BPMN vs. UML activity diagram for business process modeling. Accounting and Management Information Systems, 11(4), 637-651.

Geiger, M., Harrer, S., \& Lenhard, J. (2016). Process engine benchmarking with betsy: current status and future directions. CEUR Workshop Proceedings, 1562, 37-44.

Georges, M. R. R. (2010). Business process modeling and production control system specification in the self-adhesive industry. Journal of Information Systems and Technology Management, 7(3), 639-668. http://dx.doi.org/10.4301/S1807-17752010000300007.

Giviani, T. A. D. L., \& Argourd, A. R. T. T. (2015). Business processes management: a study from library integrated system of São Carlos. Revista Digital de Biblioteconomica e Ciência da Informação, 13(3), 526-545.

Haddar, N. Z., Makni, L. \& Abdallah, H. B. (2014). Literature review of reuse in business process modeling. Software \& Systems Modeling, 13(3), 975-989.

Huang, Z., van der Aalst, W. M. P., Lu, X., \& Duan, H. (2011). Reinforcement learning based resource allocation in business process management. Data \& Knowledge Engineering, 70(1), 127-145. http://dx.doi.org/10.1016/j.datak.2010.09.002.

Joschko, P., Widok, A. H., Appel, S., Greiner, S., Albers, H., \& Page, B. (2015). Modeling and simulation of offshore wind farm O\&M processes. Environmental Impact Assessment Review, 52, 31-39. http://dx.doi.org/10.1016/j.eiar.2014.09.009.

Keletso, L., Chioasca, E., \& Zaho, L. (2014). An integrative approach to support multi perspective business process modeling. International Journal of Services Computing, 2(1), 11-24.

Kocbek, M., Jost, G., Hericho, M., \& Polančič, G. (2015). Business process model and notation: the current state of affairs. Computer Science and Information Systems, 12(2), 509-539. http://dx.doi.org/10.2298/CSIS140610006K.

Kuo, T. C., Hsu, C. W., Huang, S. H., \& Gong, D. (2014). Data sharing: a collaborative model for a green textile/clothing supply chain. International Journal of Computer Integrated Manufacturing, 27(3), 266-280. http://dx.doi.org/10.1080/0951192X.2013.814157. 
Kuo, T. C., Hsu, C. W., Ku, K. C., Chen, P., \& Lin, C. H. (2012). A collaborative model for controlling the green supply network in the motorcycle industry. Advanced Engineering Informatics, 26(4), 941-950. http://dx.doi.org/10.1016/j.aei.2012.09.001.

Latif, K., Nadeem, A., \& Lee, G. (2011). A UML profile for real time industrial control systems. In Proceedings of the International Conference on Advanced Software Engineering and Its Applications. Berlin: Springer. http://dx.doi.org/10.1007/978-3-642-27207-3_11.

Leopold, H., Mendling, J., \& Gunther, O. (2016). Learning from quality issues of BPMN models from industry. IEEE Software, 33(4), 26-33. http://dx.doi.org/10.1109/MS.2015.81.

Malamut, G. (2005). Processes applied to integrated management systems. In Anais do $1^{\circ}$ Seminário Brasileiro de Gestão por Processos (pp. 1-20). Rio de Janeiro.

Maman, U., Sugiarti, Y., \& Kumaladewi, N. (2017). Design of e-commerce information systems for houseplants: the case of yasyifa nursery plantation. In Proceedings of the 5th International Conference on Cyber and IT Service Management (CITSM 2017). Piscataway: IEEE. http://dx.doi.org/10.1109/CITSM.2017.8089298.

Marasco, A. (2008). Third-party logistics: a literature review. International Journal of Production Economics. Research and Applications in E-Commerce and Third-Party Logistics Management, 113(1), 127-147.

Mili, H., Tremblay, G., Jaoude, G. B., Lefebvre, É., Elabed, L., \& El Boussaidi, G. (2010). Business process modeling languages: Sorting Through the Alphabet Soup. ACM Computing Surveys, 43(1), 1-56. http://dx.doi.org/10.1145/1824795.1824799.

Mohammadi, M., \& Mukhtar, M. B. (2012). Business process modelling languages in designing integrated information system for supply chain management. International Journal on Advanced Science Engineering Information Technology, 2(6), 54-57. http://dx.doi.org/10.18517/ijaseit.2.6.245.

Neubauer, T. (2009). An empirical study about the status of business process management. Business Process Management Journal, 15(2), 166-183. http://dx.doi.org/10.1108/14637150910949434.

Onggo, B. S. S., Proudlove, N. C., D’Ambrogio, S. A., Calabrese, A., Bisogno, S., \& Levialdi Ghiron, N. (2018). A BPMN extension to support discrete-event simulation for healthcare applications: an explicit representation of queues, attributes and data-driven decision points. The Journal of the Operational Research Society, 69(5), 788802. http://dx.doi.org/10.1057/s41274-017-0267-7.

Pavani, J. O., \& Scucuglia, R. (2011). Mapping and Process Management - BPM (Business Process Management) (1. ed.). São Paulo: M.Books do Brasil Editora Ltda.

Petrasch, R., \& Hentschke, R. (2016). Process modeling for industry 4.0 applications: Towards an industry 4.0 process modeling language and method. In Proceedings of the 13th International Joint Conference on Computer Science and Software Engineering (JCSSE). Piscataway: IEEE. http://dx.doi.org/10.1109/JCSSE.2016.7748885.

Pinarbaşi, M., Sel, C., Alağaş, H. M., \& Yüzükirmizi, M. (2013). Integrated definition modeling and Taguchi analysis of flexible manufacturing systems: aircraft industry application. International Journal of Advanced Manufacturing Technology, 68(9), 2169-2183. http://dx.doi.org/10.1007/s00170-013-4829-9.

Pinggera, J., Soffer, P., Fahland, D., Weidlich, M., Zugal, S., Weber, B., Reijers, H. A., \& Mendling, J. (2015). Styles in business process modeling: an exploration and a model. Software \& Systems Modeling, 14(3), 1055-1080. http://dx.doi.org/10.1007/s10270-013-0349-1.

Pyon, C. U., Woo, J. Y., \& Park, S. C. (2011). Service improvement by business process management using customer complaints in financial service industry. Expert Systems with Applications, 38(4), 3267-3279. http://dx.doi.org/10.1016/j.eswa.2010.08.112.

Rachdi, A., En-Nouaary, A., \& Dahchour, M. (2016). Liveness and reachability analysis of BPMN process models. CIT. Journal of Computing and Information Technology, 24(2), 195-207. http://dx.doi.org/10.20532/cit.2016.1002774.

Repa, V., \& Bruckner, T. (2015). Methodology for Modeling and Analysis of Business Processes (MMABP). Journal of Systems Integration, 6(4), 17-28. http://dx.doi.org/10.20470/jsi.v6i4.243.

Rostanski, M. (2013). Business process analysis with the higher education institution example. In Proceedings of the 10th International Conference on Strategic Management and its Support by Information Systems (SMSIS 2013) (pp. 173-182). Red Hook, NY: Curran Associates.

Scheruhn, H. J., Von Rosing, M., \& Fallon, R. L. (2015). Information modeling and process modeling. In M. von Rosing, A.-W. Scheer \& H. von Scheel (Eds.), The complete business process handbook (pp. 515-554). Amsterdam: Elsevier. http://dx.doi.org/10.1016/B978-0-12-799959-3.00025-2.

Seethamraju, R. (2012). Business process management: a missing link in business education. Business Process Management Journal, 18(3), 532-547. http://dx.doi.org/10.1108/14637151211232696.

Segatto, M., Pádua, S. I. D., \& Martinelli, D. P. (2013). Business process management: a systemic approach? Business Process Management Journal, 19(4), 698-714. http://dx.doi.org/10.1108/BPMJ-Jun-2012-0064.

Silva, D. (2015). Business process models: comparative analysis of notations (Master's thesis). Universidade do Minho, Portugal. Retrieved in 2018, November 19, from http://repositorium.sdum.uminho.pt/handle/1822/40163 
Silveira, D. S., Cruz, P. O. S., \& Schmitz, E. A. (2016). Heuristics for extracting business use cases from process modeling. In Minutes of the Conference of the Portuguese Association of Information Systems (Vol. 3, No. 3). Guimarães: PTAIS.

Siriram, R. (2012). A soft and hard systems approach to business process management. Systems Research and Behavioral Science, 29(1), 87-100. http://dx.doi.org/10.1002/sres.1095.

Skrinjar, R., \& Trkman, P. (2013). Increasing process orientation with business process management: critical practices'. International Journal of Information Management, 33(1), 48-60. http://dx.doi.org/10.1016/j.ijinfomgt.2012.05.011.

Smirnov, S., Weidlich, M., Mendling, J., \& Weske, M. (2012). Action patterns in business process model repositories. Computers in Industry, 63(2), 98-111. http://dx.doi.org/10.1016/j.compind.2011.11.001.

Strîmbei, C., Dospinescu, O., Strainu, R. M., \& Nistor, A. (2016). The BPMN approach of the university information systems. Ecoforum, 5(2), 181-193.

Tas, E., Yaman, H., \& Tanacan, L. (2008). A building material evaluation and selection model for the turkish construction sector. Engineering, Construction, and Architectural Management, 15(2), 149-163. http://dx.doi.org/10.1108/09699980810852673.

Toor, T. P. S., \& Dhir, T. (2011). Benefits of integrated business planning, forecasting, and process management. Business Strategy Series, 12(6), 275-288. http://dx.doi.org/10.1108/17515631111185914.

Torres, M. A. (2011). Process modeling language analysis of a supply chain reference model (Masters dissertation). Universidade Estadual Paulista "Júlio de Mesquita Filho", Bauru. Retrieved in 2018, November 19, from https://repositorio.unesp.br/handle/11449/93041

Trkman, P. (2010). The critical success factors of business process management. International Journal of Information Management, 30(2), 125-134. http://dx.doi.org/10.1016/j.jinfomgt.2009.07.003.

van der Aalst, W. M. P. (2013). Business process management: a comprehensive survey. ISRN Software Engineering, 2013, 1-37. http://dx.doi.org/10.1155/2013/507984.

Van Wel, R. (2013). Business best practices in Agile software development (Masters dissertation). Leiden University, Leiden \& Haia, Netherlands.

Vergidis, K., Turner, C. J., \& Tiwari, A. (2008). Business process perspectives: theoretical developments vs. real-world practice. International Journal of Production Economics, 114(1), 91-104. http://dx.doi.org/10.1016/j.ijpe.2007.12.009.

vom Brocke, J., \& Sinnl, T. (2011). Culture in business process management: a literature review. Business Process Management Journal, 17(2), 357-378. http://dx.doi.org/10.1108/14637151111122383.

Witsch, M., \& Vogel-Heuser, B. (2012). Towards a formal specification framework for manufacturing execution systems. IEEE Transactions on Industrial Informatics, 8(2), 311-320. http://dx.doi.org/10.1109/TII.2012.2186585.

Zarabzadeh, A., O'Donoghue, J., Adam, F., O'Connell, M., O'Connor, S., Woodworth, S., \& O'Kane, T. (2012). Moving towards a sensor-based patient monitoring system: evaluating its impact on data and information quality. In Proceedings of the 6th European Conference on Information Management and Evaluation (ECIME 2012) (pp. 342-350). Ireland: Academic Conferences \& Publishing International Ltd.

Zhang, Y., Liang, R., Shi, Z., \& Ma, H. (2012). The design and implementation of a process-driven higher educational administrative system. IERI Procedia, 2, 176-182. http://dx.doi.org/10.1016/j.ieri.2012.06.071.

Zheng, J., Feng, Y., \& Zhao, Y. (2014). A unified modeling language-based design and application for a library management information system. Cybernetics and Information Technologies, 14(5), 129-144. http://dx.doi.org/10.2478/cait-2014-0050. 